\title{
Ccr5 Regulates Inflammatory Gene Expression in Response to Encephalomyocarditis Virus Infection
}

\author{
Benjamin S. Christmann, * Jason M. Moran, * \\ Jennifer A. McGraw, ${ }^{\dagger}$ R. Mark L. Buller, ${ }^{\ddagger}$ and \\ John A. Corbett ${ }^{\dagger}$ \\ From the Edward A. Doisy Department of Biochemistry and \\ Molecular Biology, "and the Department of Molecular \\ Microbiology and Immunology, ${ }^{\ddagger}$ Saint Louis University School of \\ Medicine, Saint Louis, Missouri; and the Department of \\ Biochemistry, the Medical College of Wisconsin, Milwaukee, \\ Wisconsin
}

Encephalomyocarditis virus (EMCV) is capable of stimulating inflammatory gene expression by macrophages as a result of interactions between EMCV capsid proteins and cell surface receptors. In this study, biochemical and genetic approaches identified a role for Ccr5, a chemokine receptor, in transducing the signals of EMCV infection that result in the expression of inflammatory genes in macrophages. Antibody neutralization and gene knockout strategies were used to show that the presence of $\mathrm{Ccr} 5$ is required for EMCV-stimulated mitogen-activated protein (MAP) kinase and nuclear factor-kappa B (NF- $\kappa$ B) activation, and the subsequent expression of the inflammatory gene-inducible nitric oxide synthase (iNOS) and cyclooxygenase 2 (COX-2). Ccr5 appears to participate in the early control of virus replication: EMCV mRNA accumulates to sevenfold higher levels in Ccr5-deficient mice when compared to wild-type controls. These findings support a regulatory role for Ccr5 in the antiviral response to EMCV in which this chemokine receptor participates in regulation of inflammatory gene expression in response to virus infection. (Am J Pathol 2011, 179:2941-2951; DOI: 10.1016/j.ajpath.2011.08.012)

Pathogen-associated molecular patterns (PAMPs) allow the innate immune system to recognize invading pathogens. Double-stranded (ds)RNA, produced during the replication of most viruses, is a PAMP that functions to activate innate immunity in response to virus infections. ${ }^{1}$ Two mechanisms have been described for the sensing of viral RNA:cytosolic dsRNA receptors and Toll-like recep- tor (TLR) 3. Cytoplasmic dsRNA sensors such as dsRNAdependent protein kinase $R(P K R)$, retinoic acid-inducible gene-I (RIG-I), and melanoma differentiation antigen 5 (mda-5) allow cells to detect intracellular dsRNA produced during virus infection. PKR is a serine kinase that is activated by autophosphorylation after binding to dsRNA. ${ }^{2,3}$ Once activated, PKR phosphorylates eukaryotic initiation factor (elF) $2 \alpha$, preventing guanine nucleotide exchange, thereby inhibiting general protein translation and, consequently, virus replication. RIG-I and mda-5 contain $\mathrm{N}$-terminal caspase recruitment domains (CARD) and C-terminal RNA helicase domains. ${ }^{4,5}$ Both RIG-I and mda-5 use the CARD domain adaptor mitochondrial antiviral signaling protein (MAVS) to activate antiviral gene expression after dsRNA binding to their helicase domain. ${ }^{6}$ As a result of its localization in endosomes, TLR3 recognizes extracellular dsRNA that accumulates in cells after endocytosis. ${ }^{7-9}$ In this context, TLR3 may not sense dsRNA produced in cells during viral infection, but is likely responsible for sensing dsRNA released from cells undergoing lysis. ${ }^{9,10}$

One target shared by each of the dsRNA sensing receptors is the transcription factor nuclear factor (NF)$\kappa \mathrm{B} . \mathrm{NF}-\kappa \mathrm{B}$ is held in the cytoplasm in an inactive complex with inhibitory protein $(\mathrm{I}) \boldsymbol{\kappa} \mathrm{B}$. After phosphorylation by an $I_{\kappa} \mathrm{B}$ kinase $(\mathrm{IKK}),\left.\right|_{\kappa} \mathrm{B}$ is targeted for degradation, allowing $\mathrm{NF}-\kappa \mathrm{B}$ to translocate to the nucleus to activate gene expression. ${ }^{11}$ dsRNA signaling through dsRNA receptors TLR3, PKR, RIG-I, or mda-5 is capable of activating NF$\kappa \mathrm{B}$. $^{5,8,12}$ Along with NF- $\kappa \mathrm{B}$, the interferon regulatory factors (IRF)-3 and -7 also participate in the expression and production of type 1 interferons (IFNs) and the induction of type 1 IFN-dependent gene expression. ${ }^{13,14}$ Virus infection can also activate an additional response that is characterized by the production of interleukin-1 $\beta$ (IL-1 $\beta)$, tumor necrosis factor (TNF), inducible nitric oxide synthase (iNOS), and cyclooxygenase-2 (COX-2). In re-

\footnotetext{
Supported by NIH grants DK52194 and Al-44458 (J.A.C.).

Accepted for publication August 4, 2011

Supplemental material for this article can be found at http://ajp. amjpathol.org or at doi: 10.1016/j.ajpath.2011.08.012.

Address reprint requests to John A. Corbett, Ph.D., Medical College of Wisconsin, Department of Biochemistry, 8701 Watertown Plank Rd., Milwaukee, WI. E-mail: jcorbett@mcw.edu
} 
sponse to EMCV, macrophage expression of these inflammatory gene products is dependent on NF- $\mathrm{KB},{ }^{15}$ and the activation of a secondary signaling pathway that is selective for the target gene of interest. The secondary signaling pathways include extracellular signal-regulated kinase (ERK) activation for IL-1 $\beta$ expression, ${ }^{16}{ }^{\mathrm{iPLA}}{ }_{2}$ activation for iNOS, ${ }^{17,18}$ and Jun N-terminal kinase (JNK) and p38 activation for COX-2. ${ }^{19}$

The ability of EMCV to rapidly activate multiple signaling cascades (within 15 minutes after infection) raises the possibility that structural components of EMCV, in addition to viral RNA produced during replication, may be capable of activating antiviral and inflammatory signaling pathways. Consistent with this possibility, we have shown that EMCV capsid protein, void of viral RNA, stimulates MAP kinase and NF- $\kappa \mathrm{B}$ activation and iNOS and IL-1 $\beta$ expression in macrophages to levels similar to those induced by the intact, RNA-containing virus. ${ }^{20}$ These findings suggest that EMCV capsid proteins contain structural motifs that could be recognized by surface receptors on macrophages, and that this interaction may result in the initiation of proinflammatory signaling.

Ccr5 is a $41-\mathrm{kDa}$ cell surface $\mathrm{G}$ protein-coupled receptor expressed on T cells, macrophages, and dendritic cells that interacts with chemokine ligand (Ccl) $3 / \mathrm{MIP} 1 \alpha$, Ccl4/MIP1 $\beta$, or Ccl5/regulated on activation normal T cell expressed and secreted (RANTES). ${ }^{21-23} \mathrm{Ccr} 5$ has also been shown to function as a coreceptor for macrophagetropic HIV infection ${ }^{24,25}$ by interacting with gp120 on the V3 loop of the HIV envelope. ${ }^{26} \mathrm{Ccr} 5$ has been identified as a receptor for bacterial hsp 70, resulting in activation of dendritic cells. ${ }^{27}$ Because empty EMCV capsid (void of viral RNA) is capable of activating inflammatory gene expression, ${ }^{20}$ and foreign proteins (such as bacterial hsp 70) are capable of activating cells by interacting with Ccr5, the possibility that Ccr5 may participate in the response of macrophages to EMCV infection was examined. Using antibody neutralization and mice deficient in $\mathrm{Ccr}^{-/-}$, evidence is presented to support a role for $\mathrm{Ccr} 5$ in transducing the signals that regulate inflammatory gene expression by macrophages in response to EMCV infection.

\section{Materials and Methods}

\section{Cell Culture, Animals, and Antibodies}

Dulbecco's modified Eagle's medium (DMEM) containing $10 \%$ heat-inactivated FCS and L-glutamine was obtained the Washington University Tissue Culture Support Center (St. Louis, MO). Fetal calf serum, L-glutamine, penicillin, and streptomycin were obtained from Invitrogen Life Technologies (Carlsbad, CA). Poly IC was purchased from Sigma-Aldrich (St. Louis, MO) and was prepared for use as previously described ${ }^{28}$ Enhanced chemiluminescence reagents were purchased from Amersham Biosciences/GE Healthcare (Little Chalfont, UK). HRP-conjugated donkey anti-rabbit IgG and HRP-conjugated donkey anti-mouse IgG were purchased from Jackson ImmunoResearch Laboratories (West Grove, PA).
RAW264.7 cells were obtained from Washington University Tissue Culture Support Center and cultured in complete DMEM (containing 10\% fetal calf serum, $100 \mathrm{U} / \mathrm{mL}$ penicillin, and $100 \mu \mathrm{g} / \mathrm{mL}$ streptomycin). C57BL/6J mice were purchased from Harlan Laboratories (Indianapolis, IN) and wild type B6/129, CCr5 ${ }^{-/-}$and $T L R 3^{-/-}$mice were purchased from The Jackson Laboratory (Bar Harbor, ME). Breeding pairs of $\mathrm{Ccr}^{-/-}$(B6/129) mice were a gift from Dr. Michael Holtzman, Washington University School of Medicine (St. Louis, MO). Wild-type and mda$5^{-1-}$ macrophages were prepared as previously described and provided by Dr. Marco Colonna (Washington University). ${ }^{29}$ All animal use was approved by and in accordance with Saint Louis University and the Medical College of Wisconsin Animal Welfare guidelines. Rabbit anti-COX-2 and rabbit anti-iNOS antisera were obtained from Cayman Chemical (Ann Arbor, MI). Rabbit antiphospho-p38, rabbit anti-phospho-JNK, and rabbit antiphospho-ERK were obtained from Promega (Madison, WI). Goat anti-Ccr5 and rabbit anti-p38 antisera were obtained from Santa Cruz Biotechnology (Santa Cruz, CA). Mouse anti-GAPDH antiserum was purchased from Ambion (Foster City, CA). Mouse 3B7 antiserum and rabbit anti-Mengo (neutralizing EMCV antibody) were provided by Dr. Ann Palmenberg (University of Wisconsin). Mouse anti-pro-IL-1 $\beta$ 3ZD was obtained from the National Institutes of Health. All other reagents were obtained from commercially available sources.

\section{Peritoneal Macrophage Isolation and Cell Culture}

Non-elicited naive peritoneal exudate cells (PEC) were harvested from mice by lavage as previously described. ${ }^{30}$ After isolation, $2 \times 10^{5}$ cells in $500 \mu \mathrm{L}$ of DMEM were incubated at $37^{\circ} \mathrm{C}$ under an atmosphere of $95 \%$ air $5 \% \mathrm{CO}_{2}$ for at least 12 hours before initiation of experiments. These naive PEC were used for all experiments, with the exception of studies performed using PEC isolated from $\mathrm{Mda}^{-1-}$ mice. Thioglycolate-elicited PEC isolated from wild-type and $M \mathrm{Ma}^{-1-}$ mice were kindly provided by Dr. Marco Colonna (Washington University, St. Louis) using previously described methodologies. ${ }^{29}$ Experiments were initiated by treatment with 50 $\mu \mathrm{g} / \mathrm{mL}$ poly IC or 1 multiplicity of infection (MOI) EMCV (with or without IFN- $\gamma$ ). RAW 264.7 cells were removed from growth flasks by treatment with $0.05 \%$ trypsin and $0.02 \%$ EDTA for 5 minutes at $37^{\circ} \mathrm{C}$. Cells were washed twice with DMEM, plated at a density of $2 \times 10^{5}$ cells/500 $\mu \mathrm{L}$ DMEM. These cells were cultured for at least 2 to 3 hours (and up to 24 hours) before initiation of experiments.

\section{Nitrite Determination}

Nitrite production was determined by adding $50 \mu \mathrm{L}$ of the Greiss reagent to $50 \mu \mathrm{L}$ of culture supernatant. ${ }^{31}$ The absorbance was measured at $540 \mathrm{~nm}$, and nitrite concentrations were calculated from a sodium nitrite standard curve. 


\section{Virus Propagation and Infection}

The B variant of EMCV was a generous gift of Ji-Won Yoon (University of Calgary, Calgary, AB, Canada) and has been previously described. ${ }^{32}$ EMCV was propagated in L929 cells, supernatants were clarified by centrifugation, and virus titers were determined by a plaque assay. Cell monolayers were infected with a multiplicity of infection of 1 plaque-forming unit per cell by the addition of EMCV to the culture medium for the indicated times at $37^{\circ} \mathrm{C}$. Empty EMCV capsid (hiEMCV) was prepared by heating for 20 minutes at $54^{\circ} \mathrm{C}$ to liberate viral genomic RNA, followed by RNase treatment to digest free viral RNA as previously described by our laboratory. ${ }^{20}$ The amount of hiEMCV used for experiments was equivalent to the amount used to provide a final infection of $1 \mathrm{MOI}$. For in vivo studies, mice were infected with $6 \times 10^{5}$ plaque-forming units of EMCV in 50 $\mu \mathrm{L}$ of normal saline via intraperitoneal injection or $50 \mu \mathrm{L}$ of sham control prepared by dilution of supernatant obtained from sham-infected L929 cells using dilutions identical to those used to prepare EMCV. Twenty hours after infection, blood was collected via heart stick for serum analysis, and naive PEC were harvested by peritoneal lavage for RNA isolation using the RNeasy RNA isolation kit (Qiagen, Valencia, CA).

\section{Western Blot Analysis}

Protein samples were separated by SDS-PAGE and transferred to nitrocellulose membranes (Amersham Biosciences) under semidry transfer conditions as previously described. ${ }^{33,34}$ Antibody dilutions were 1:1000 for all primary antibody incubations and 1:7000 for all HRP-conjugated secondary antibody incubations. Antigen was detected by enhanced chemiluminescence according to the manufacturer's specifications (Amersham Biosciences).

\section{ELISA Analysis}

Type IFN $\alpha$ ELISAs were purchased from Pestka Biomedical Laboratories (Piscataway, NJ) and performed according to the manufacturer's protocol.

\section{PCR Analysis}

Total RNA was isolated from macrophages using the RNeasy RNA isolation kit (Qiagen). First-strand cDNA synthesis was performed using oligo(dT) and reverse transcriptase. Standard PCR was performed as previously described. ${ }^{19}$ Real-time PCR analysis was performed on cDNA samples using Quantitect SYBR Green reagent (Qiagen) and the MJ Research DNA Engine Opticon System (BioRad, Hercules, CA). The Pfaffl comparative threshold cycle method was used to quantify the relative levels of gene expression and was normalized to the housekeeping gene $\mathrm{GAPDH} .{ }^{35} \mathrm{cDNAs}$ were amplified using the following primers: 5'-CGAGACTTCTGTGACACACAGC-3' and 5'-CATCTCCTGGTGGAACACAGGG-3' for iNOS, 5'-TाTGTGAGTCATTCACCAGACAGAT-3' and 5'-CAGTATTGAGGAGAACAGATGGGATT-3' for COX-2, 5'-CCTGTGGCCTTGGGCCTCAA-3' and 5'-GGTGCTGATGTACCAGTTGGG-3' for IL-1 $\beta$, and 5'-GCTGGGGCTCACCTGAAGGG-3' and 5'-GGATGACCTTGCCCACAGCC-3' for GAPDH, 5'-GGAGTTGAGAATGCTGAGAG-3' and 5'-TTCCAGCATAAGGACTCCAG-3' EMCV, 5'-GGCTTCATCTGCTGCTTGGAATAC-3' and $5^{\prime}$-TCCTTCTCTTCACTCAGTCTTGGC-3' for IFN $\alpha$, 5'GCACTGGGTGGAATGAGACTATTG-3' and 5'-TCTGAGGCATCAACTGACAGGTC-3' for IFN $\beta$.

\section{Statistics}

Statistical comparisons were made between groups using one-way analysis of variance. Significant differences between groups $(P<0.05)$ were determined by Newman-Keuls post hoc analysis.

\section{Results}

mda-5 and TLR3 as Regulators of Macrophage Inflammatory Gene Expression in Response to EMCV

The dsRNA sensors PKR, TLR3, mda-5, and RIG-I are localized in the cytoplasm, either free or associated with intracellular organelles. ${ }^{36}$ In previous studies, we have shown that PKR is not required for dsRNA- or EMCV-induced $\mathrm{NF}-\kappa \mathrm{B}$ activation or inflammatory gene expression by macrophages. ${ }^{20,28}$ Gitlin et $\mathrm{al}^{29}$ have shown that mda-5 is the primary dsRNA sensor that is activated and responsible for the production of type $1 \mathrm{IFN}$ in response to EMCV infection. Using elicited macrophages harvested from wild-type and mda-5-deficient mice, the potential role of this helicase domain containing dsRNA receptors in regulating inflammatory gene expression was examined. Infection of wildtype and mda5 $^{-1-}$ macrophages with EMCV results in a similar rapid activation of MAP kinases as determined by Western blot analysis of phosphorylated ERK, p38, and JNK that is detected as early as 15 minutes after infection. Using $\mid \kappa \mathrm{B} \alpha$ degradation as an index of NF- $\kappa \mathrm{B}$ activation, EMCV infection also stimulates the rapid activation of $\mathrm{NF}-\kappa \mathrm{B}$ in a similar temporal fashion (Figure 1A). These findings suggest that mda-5 is not essential for the activation of these inflammatory signaling pathways in response to EMCV infection. Consistent with this hypothesis, EMCV stimulates the production of pro-IL- $1 \beta$ to similar levels in macrophages isolated from wild-type and $\mathrm{mad}-5^{-/-}$mice (Figure 1B). Macrophages require two proinflammatory signals for the expression of a number of inflammatory genes, including iNOS, ${ }^{37,38}$ with IFN- $\gamma$, EMCV stimulates an increase in iNOS and COX-2 protein expression (Figure 1, B and C) and nitric oxide production (Figure 1D) to similar levels in wild-type

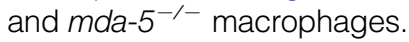

The potential role of TLR3, a dsRNA receptor and activator of antiviral responses that differs in both location and signaling properties from PKR and mda-5, was examined as a potential mediator of MAP kinase activation and inflammatory gene expression in macrophages in response to EMCV infection. As shown in Figure 2, EMCV-stimulates $I_{\kappa} \mathrm{B}$ degradation (Figure $2 \mathrm{~A}$ ) and, in combination with IFN- $\gamma$, stimulates iNOS and IL- $1 \beta$ protein expression to similar levels in macrophages isolated 


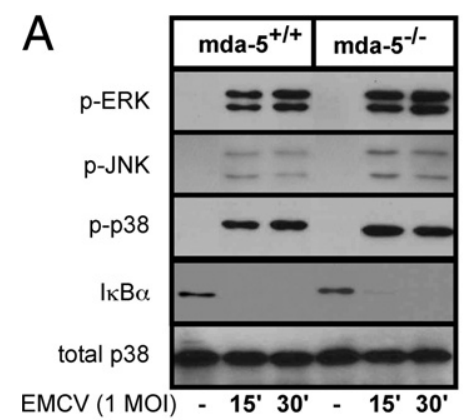

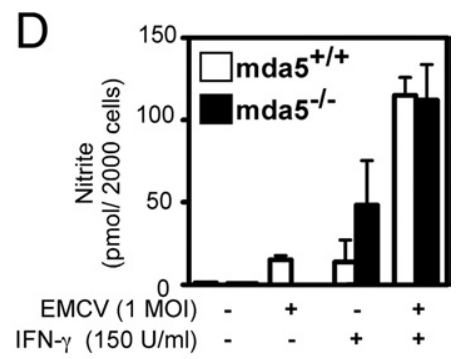

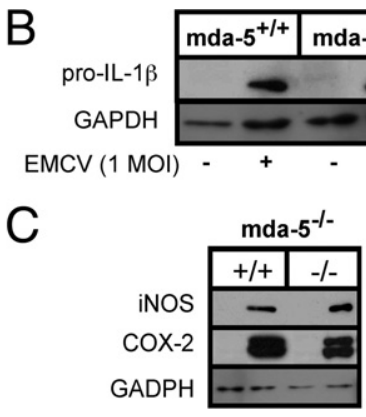

$\operatorname{EMCV}(1 \mathrm{MOI})+\ldots+++$

IFN- $\gamma(150 \mathrm{U} / \mathrm{ml})$

Figure 1. Role of mda-5 in EMCV-stimulated MAP kinase and NF- $\kappa \mathrm{B}$ activation and inflammatory gene expression. EMCV stimulates ERK, JNK, and p38 phosphorylation and $\mathrm{I} \kappa \mathrm{B} \alpha$ degradation (Western blot analysis) in thioglycolate-elicited peritoneal macrophages isolated from mda- $5^{+/+}$and $m d a-5^{/-}$mice 15 and 30 minutes after infection (A). Total p38 is shown as a loading control. EMCV stimulates IL-1 $\beta$ (B), and EMCV + IFN- $\gamma$ stimulate iNOS and COX-2 (C) expression as determined by Western blot analysis and nitrite production (D) to similar levels in macrophages isolated from mda- $5^{+/+}$and $m d a-5^{/-}$mice 24 hours after infection. GAPDH is shown as a loading control (B and $\mathbf{C})$. Results are representative of 3 experiments $(\mathbf{A}-\mathbf{C})$ or the average \pm SEM of three independent experiments $(\mathbf{D})$. Nitrite formation between macrophages isolated from wild-type and mda-5-deficient mice are not statistically different.

from wild-type and $T L R 3^{-\prime-}$ mice (Figure $2 \mathrm{~B}$ ). These findings are consistent with the absence of any inhibitory effect of TLR3 deficiency on expression of COX-2 or p38 activation in response to EMCV infection, ${ }^{19}$ and suggest that much like PKR, ${ }^{16,18,39}$ mda-5 and TLR3 are not required for EMCV-stimulated MAP kinase or NF- $\kappa \mathrm{B}$ activation, or for inflammatory gene expression by macrophages.

The dsRNA sensors TLR3 and mda- 5 are required for the production of type 1 IFNs by macrophages in response to dsRNA or EMCV infection. There is a reduction in the amount of type 1 IFN production in response to synthetic dsRNA (poly IC) by mouse macrophages isolated from TLR3-deficient mice as compared to wild-type controls (Figure 3A). Consistent with the previously described role of mda- 5 in type 1 IFN response, ${ }^{29}$ there is an attenuation in the accumulation of type 1 IFN mRNA in EMCV-infected macrophages (with or without IFN- $\gamma$ ) iso-

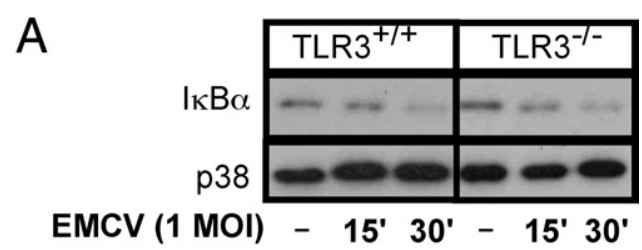

B

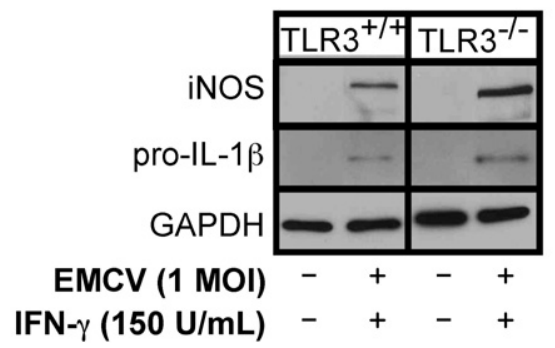

Figure 2. Role of TLR3 in EMCV-stimulated in MAP kinase and NF- $\kappa$ B activation and inflammatory gene expression. EMCV stimulates the degradation of $\mathrm{I} \kappa \mathrm{B} \alpha$ to similar levels in naive peritoneal macrophages isolated from wild-type or TLR3 ${ }^{-1-}$ mice after 15 - and 30-minute incubations with $1 \mathrm{MOI}$ EMCV, as determined by Western blot analysis (A). Total p38 is shown as a loading control. EMCV + IFN- $\gamma$ stimulates iNOS and IL- $1 \beta$ expression to similar levels in macrophages isolated from wild-type and TLR ${ }^{-/}$macrophages (B). GAPDH is shown as a loading control. Results are representative of three independent experiments. lated from $m d a-5^{-/}$mice as compared to macrophages isolated from wild-type control mice (Figure 3B). These findings suggest that the mechanisms responsible for the control of inflammatory gene expression in response to EMCV infection differ from the mechanisms responsible for the production of antiviral type 1 IFN.

\section{Inflammatory Gene Expression Is Stimulated by EMCV Capsid Protein Devoid of Viral RNA}

The treatment of macrophages with EMCV capsid (void of RNA) results in the activation of ERK, CREB, and NF-
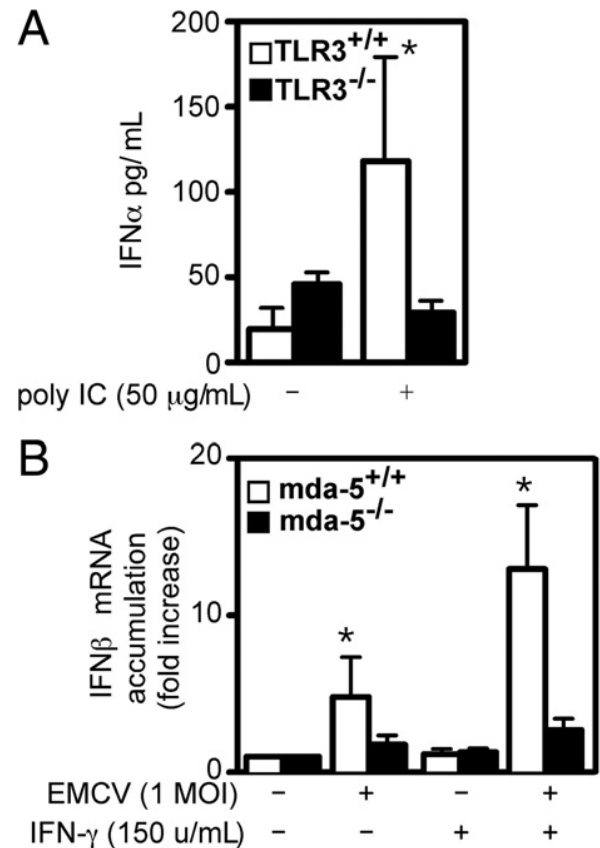

Figure 3. Regulation of type I IFN production by TLR3 and mda-5. Peritoneal macrophages isolated from naive wild-type, TLR $3^{-1-}$ (A), or thioglycolate-elicited $m d a-5^{-1}$ (B) mice were treated for 16 hours with $50 \mu \mathrm{g} / \mathrm{mL}$ poly IC, EMCV, or EMCV + IFN- $\gamma$; type 1 IFN release was determined by ELISA (A), and mRNA accumulation (B) was evaluated by real-time PCR on total RNA isolated from cultured cells. Results are the average \pm SEM of three independent experiments $\left({ }^{*} P \leq 0.05\right.$ vs control). 
A

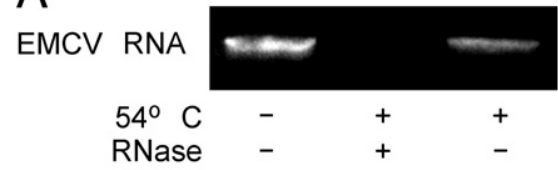

C

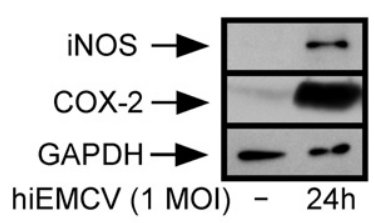

B

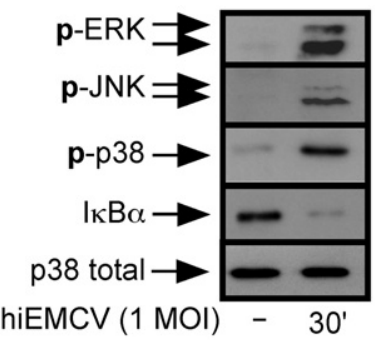

D Depletion $\mathrm{Ab}$

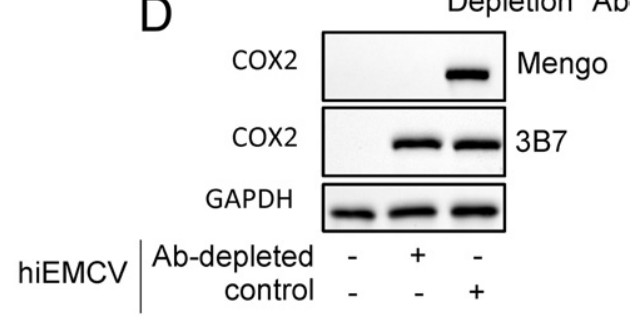

Figure 4. Heat-inactivated and RNase-treated EMCV stimulates inflammatory gene expression. (A) Incubation for 20 minutes at $54^{\circ} \mathrm{C}$, followed by RNase treatment, depletes EMCV of virus RNA as determined by PCR. RNA-depleted EMCV (hiEMCV) stimulates ERK, JNK, and p38 phosphorylation, and $\mathrm{I} \kappa \mathrm{B} \alpha$ degradation after a 30-minute incubation (B) and COX-2 and iNOS expression after a 24-hour incubation (C) as determined by Western blot analysis. Total p38 and GAPDH are shown as loading controls. hiEMCV was subject to immunodepletion using a rabbit anti-EMCV developed against Mengo capsid protein (MENGO), a mouse monoclonal antibody that targets EMCV polymerase (37B), or rabbit/mouse serum as antibody controls (control). RAW 264.7 macrophages were treated with 1 MOI of the depleted hiEMCV preparations, cultured for 24 hours, and then COX-2 expression was determined by Western blot analysis. Note that the antibody targeting EMCV capsid protein (Mengo) depletes the EMCV preparation of the active component stimulating COX-2 expression, whereas targeting the virus polymerase does not inhibit COX-2 expression by hiEMCV. Results are representative of three independent experiments (B-D). Ab, antibody. $\kappa \mathrm{B}$, and the expression of $\mathrm{IL}-1 \beta$ and $\mathrm{NOS} .{ }^{20}$ hiEMCV is prepared by heating for 20 minutes at $54^{\circ} \mathrm{C}$ to liberate viral genomic RNA, ${ }^{40}$ followed by RNase treatment to digest free viral RNA. ${ }^{20}$ Treatment of macrophages with a volume of EMCV devoid of detectable EMCV RNA (hiEMCV; Figure 4A) equal to $1 \mathrm{MOI}$ of intact EMCV for 30 minutes results in the phosphorylation of ERK, JNK, and $\mathrm{p} 38$, and the degradation of $\mathrm{I}_{\mathrm{KB}}$ (Figure $4 \mathrm{~B}$ ). Consistent with activation of these signaling pathways, hiEMCV stimulates iNOS and COX-2 expression by macrophages (Figure 4C). These findings are consistent with our previous studies showing that hiEMCV activates signaling cascades regulating inflammatory gene expression. ${ }^{20}$

To confirm that EMCV capsid protein is responsible for stimulating inflammatory gene expression, the effects of antibody depletion of EMCV from the virus preparation on COX-2 expression by RAW264.7 macrophages was examined. Two different antibodies were used to deplete EMCV. The first was rabbit anti-EMCV (Mengo) developed by the Palmenberg laboratory (University of Wisconsin) to Mengo, a strain of encephalomyocarditis virus. This antibody has been shown to target capsid protein and to neutralize EMCV and Mengo. ${ }^{41}$ The second antibody was mouse monoclonal $3 \mathrm{~B} 7$, which targets the EMCV polymerase and does not appear to neutralize EMCV. ${ }^{42}$ hiEMCV was prepared as outlined in Materials and Methods and then incubated for 1 hour at $4^{\circ} \mathrm{C}$ with a 1:100 dilution of rabbit anti-EMCV (Mengo) or mouse anti-3B7. The antibodies were immunoprecipitated, and the supernatants, isolated by centrifugation, were added to macrophages using an amount equivalent to an $\mathrm{MOI}$ of 1 for the hiEMCV preparation. Immunodepletion using the 37B monoclonal antibody had no effect on EMCV-stimulated COX-2 expression, whereas the expression of COX-2 was attenuated using supernatants derived from hiEMCV perpetrations depleted with the rabbit polyclonal Mengo (Figure 4D). Control immunodepletion studies using serum of the same species as the depletion antibodies (rabbit and mouse sera) did not influence EMCVstimulated COX-2 expression by macrophages (Figure 4D). These findings indicate that capsid protein mediates the activation of signaling cascades and inflammatory gene expression by macrophages treated with EMCV.

The ability of EMCV capsid protein (in the absence of viral RNA) to activate inflammatory gene expression suggests that EMCV capsid protein may function as a ligand (either directly or indirectly via a binding partner) for a cell surface receptor, and that activation of this receptor may be responsible for controlling the signaling cascades regulating inflammatory gene expression in response to EMCV infection. Furthermore, this receptor would likely be in addition to the classical dsRNA receptors, because hiEMCV is void of virus RNA, and classical dsRNA receptors are not required for inflammatory gene expression (Figures 1, 2, and 3). This hypothesis is not unprecedented; gp120 is an HIV coat protein that stimulates the expression of COX-2 in neuroblastoma cells by pathways that requires both JNK and p38 activation in addition to NF- $\kappa \mathrm{B} .{ }^{43}$ In addition, the induction of COX-2 expression by EMCV infected macrophages is dependent on the activation of JNK, p38, and $\mathrm{NF}-\kappa \mathrm{B},{ }^{15}$ and empty EMCV capsid protein stimulates COX-2 expression in macrophages (Figure 4C).

\section{Ccr5 Is Required for Macrophage Inflammatory Gene Expression in Response to EMCV}

Ccr5 is a $\mathrm{G}$ protein-coupled chemokine receptor that has been shown to recognize foreign molecules such as those found in bacterial heat shock proteins ${ }^{27}$ and viral proteins. ${ }^{26}$ To test whether Ccr5 may serve as a signaling receptor for EMCV coat protein, RAW264.7 macrophages were pretreated with a neutralizing antibody specific to the $19 \mathrm{~N}$-terminal amino acids of $\mathrm{Ccr}^{44}$ for 4 hours before stimulation with hiEMCV. Antibody neutralization of Ccr5 results in the attenuation of hiEMCV-induced p38, JNK, and ERK phosphorylation and NF- $\kappa \mathrm{B}$ activation ( $\kappa \mathrm{B}$ degradation) at 30 minutes after infection (Figure 5A). Consistent with the inhibition of cell signaling, antibody neutralization of Ccr5 attenuates both hiEMCV-stimulated COX-2 and hiEMCV + IFN- $\gamma$-stimulated iNOS expression and nitric oxide production by RAW 264.7 cells (Figure 5, B-D). Pretreatment with 
goat serum as a control for the Ccr5-blocking antibody fails to attenuate hiEMCV-stimulated activation of proinflammatory signaling cascades (Figure 5A).

Consistent with what occurs with empty EMCV capsid, pretreatment of RAW 264.7 macrophages with a Ccr5 neutralizing antibody attenuates ERK, JNK, and p38 phosphorylation and $I_{\kappa} B$ degradation in response to EMCV infection (Figure 6A). EMCV-stimulated COX-2 (Figure 6B) and iNOS expression and nitric oxide production (in combination with IFN- $\gamma$; Figure 6, C and D) by RAW264.7 macrophages is also attenuated by pretreatment with a Ccr5 blocking antibody, similar to the effects observed with the hiEMCV. We show, as a control, that goat serum fails to modulate any of the stimulatory actions of EMCV (Figure 6, A and B). These data, in combination with Figure 5, support a role for Ccr5 in transducing signals in macrophages that ultimately leads to the expression of inflammatory genes in response to EMCV capsid protein.

\section{Macrophage Activation by EMCV Is Attenuated in the Absence of Ccr5}

To confirm the antibody neutralization studies, the effects of EMCV infection on the activation of macrophages prepared from mice deficient in Ccr5 was compared to macrophages isolated from wild-type mice. Infection of mouse macrophages for 4 hours with EMCV, in the presence of IFN- $\gamma$, results in the accumulation of iNOS, COX-2, and $I L-1 \beta$ mRNA as determined by real-time PCR. The accumulation of iNOS, COX- 2 , and IL- $1 \beta$ mRNA is attenuated in macrophages isolated from $\mathrm{Ccr}^{-1-}$ mice as compared to macrophages isolated from wild-type control mice (Figure 7A). Consistent with reductions in inflammatory gene mRNA accumulation, EMCV-stimu- lated JNK, ERK, and p38 phosphorylation (Figure 7B) and EMCV + IFN- $\gamma$-stimulated iNOS, IL-1 $\beta$, and COX-2 protein expression and nitric oxide production by macrophages isolated from Ccr5-deficient mice are attenuated when compared to wild-type control macrophages (Figures 7, C and D). These findings suggest $\mathrm{Ccr} 5$ is required for EMCV to activate MAP kinases and to stimulate inflammatory gene expression. Although less sensitive to EMCV, macrophages isolated from $\mathrm{Ccr}^{-/-}$mice are responsive to extracellular signals, because LPS stimulates p38 phosphorylation and COX-2 expression to levels similar to the levels induced in wild-type macrophages (Figure 7, E and F).

Evidence provided in Figures 5, 6, and 7 supports a role for Ccr5 in the sensing of EMCV infection and the induction of inflammatory gene expression by macrophages. To confirm that Ccr5 functions in vivo in the regulation of inflammatory responses to EMCV infection, wild-type and $\mathrm{Ccr}^{-/-}$mice were infected with $6 \times 10^{5}$ plaque-forming units of EMCV in $50 \mu \mathrm{L}$ of normal saline via intraperitoneal injection. Twenty hours after infection, naive peritoneal macrophages were harvested by lavage, and the expression of iNOS and COX-2 by PEC was quantified by real-time PCR and normalized to GAPDH mRNA accumulation to normalize expression levels between mice. In mice lacking Ccr5, iNOS, and COX-2 mRNA accumulation in macrophages is attenuated as compared to macrophages harvested from wild-type control mice (Figure 8A). Importantly, the attenuation of this inflammatory gene response is associated with enhanced viral burden in infected animals, because EMCV mRNA accumulates to levels approximately sevenfold greater in PEC isolated from Ccr5-deficient mice, as compared to its accumulation in macrophages from wild-type

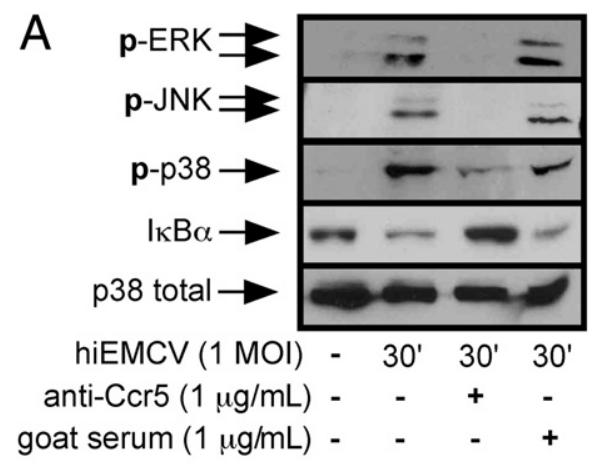

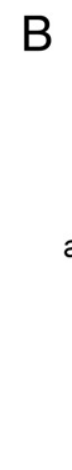
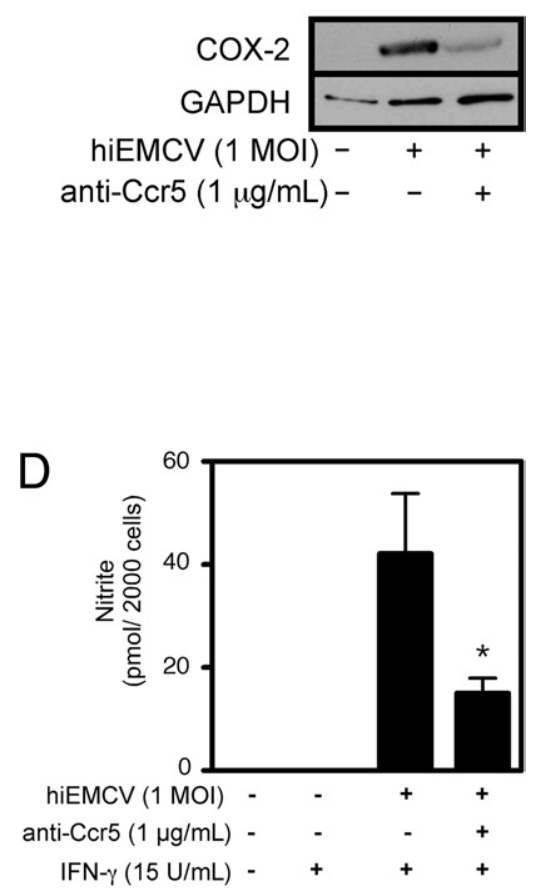

Figure 5. Antibody neutralization of $\mathrm{Ccr} 5$ attenuates macrophage activation in response to EMCV capsid protein. The stimulatory actions of 30-minute incubation of RAW 264.67 cells with hiEMCV (RNA-depleted) on ERK, JNK, and p38 phosphorylation and $\mathrm{I} \kappa \mathrm{B} \alpha$ degradation are attenuated by the antibody neutralization of $\mathrm{Ccr} 5$ (A). Consistent with the impairment in cell signaling, antibody neutralization of $\mathrm{Ccr} 5$ attenuates hiEMCV + IFN- $\boldsymbol{\gamma}$-timulated COX- 2 and iNOS expression as determined by Western blot analysis (B and $\mathbf{C}$ ) and nitrite formation (D) Results are representative of three independent experiments (A-C) or the average \pm SEM of three independent experiments $\left({ }^{*} P \leq 0.05\right.$ vs hiEMCV + IFN- $\gamma$ ). 
A

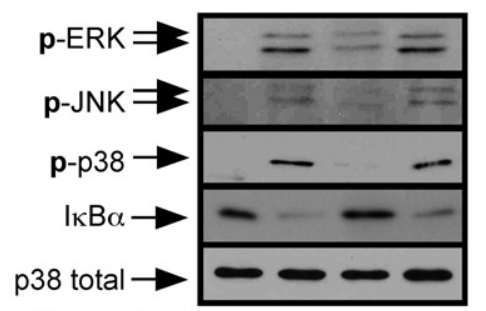

$\operatorname{EMCV}(1 \mathrm{MOI}) \quad-30^{\prime} \quad 30^{\prime} \quad 30^{\prime}$

anti-Ccr5 $(1 \mu \mathrm{g} / \mathrm{mL})-\quad+\quad+$

goat serum $(1 \mu \mathrm{g} / \mathrm{mL})$ - $\quad-\quad-\quad+$

C

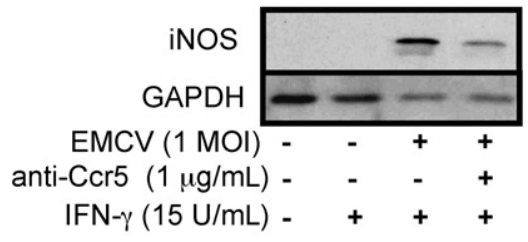

$B$

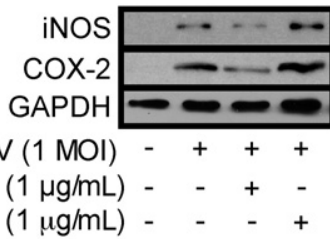

D

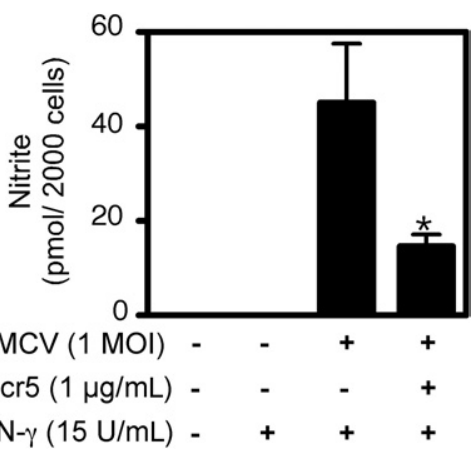

Figure 6. Antibody neutralization of $\mathrm{Ccr} 5$ attenuates EMCV-stimulated MAP kinase and NF- $\kappa \mathrm{B}$ activation and inflammatory gene expression by macrophages. Western blot analysis was used to show that the stimulatory actions of a 15- to 30-minute incubation of RAW 264.67 cells with EMCV on ERK, JNK, and p38 phosphorylation and $\mathrm{I} \kappa \mathrm{B} \alpha$ degradation are attenuated by the antibody neutralization of $\mathrm{Ccr} 5$ (A). Consistent with the impairment in cell signaling, neutralization of $\mathrm{Ccr} 5$ attenuates EMCV-stimulated or EMCV + IFN- $\gamma$-stimulated COX-2 and iNOS expression as determined by Western blot analysis (B and $\mathbf{C})$ and nitrite formation (D). Nonspecific goat serum was used to control for nonspecific effects of goat anti-Ccr5 neutralization ( $\mathbf{A}$ and $\mathbf{B}$. Results are representative of three independen experiments $(\mathbf{A}-\mathbf{C})$ or the average \pm SEM $(\mathbf{D})$ of three independent experiments $\left({ }^{*} P<0.05\right.$ $\mathrm{EMCV}+\mathrm{IFN}-\gamma$ vs EMCV + IFN- $\gamma+$ anti-Ccr 5$)$. mice (Figure 8B). EMCV mRNA levels are normalized to GAPDH mRNA accumulation. These findings support a role for Ccr5 in regulating proinflammatory gene expression in response to EMCV and that enhanced expression of these inflammatory mediators may be a potential mechanism to limit virus infection/replication. Despite an attenuation in the accumulation of inflammatory gene mRNA, the type 1 IFN response remains intact in $\mathrm{Ccr} 5^{-1-}$ mice, as serum IFN $\alpha$ levels are elevated 20 hours after EMCV infection of wild-type and $\mathrm{Ccr}^{-1-}$ mice (Figure $8 \mathrm{C})$. In addition, the enhanced virus burden in peritoneal cells correlates with increases in the level of type 1 IFN accumulation in $\mathrm{CCR} 5^{-/-}$mice after EMCV infection.

\section{Discussion}

Many of the cellular responses to viral infection are triggered by dsRNA that is produced either during replication in infected cells or taken up by endocytosis. 1,9,36 The antiviral responses that are activated by dsRNA are sensed by the cytosolic kinase PKR, 2,3,45 the endosomelocalized TLR3, 7,8,46 and cytoplasmic dsRNA sensors mda-5 and RIG-I. ${ }^{4,5}$ Although each of these dsRNA sensors has been implicated in the regulation of inflammatory gene expression in response to viral infection or synthetic dsRNA, ${ }^{9,36,47,48}$ most studies have shown the importance of these dsRNA sensors working through $\mathrm{NF}-\kappa \mathrm{B}$ and IRF3 and IRF7 to stimulate type $1 \mathrm{IFN}$ production and induction of a type 1 IFN antiviral response..$^{2,3,45}$ In addition to type 1 IFN production, virus infection also stimulates the expression of the inflammatory gene products such as iNOS, COX-2, and cytokines IL-1 $\beta$ and TNF. ${ }^{15,49}$ We have shown that inflammatory gene expression by macrophages in response to EMCV infection requires the activation of $\mathrm{NF}-\kappa \mathrm{B}$ and a second signaling cascade selective for the target gene of interest (ERK for $I L-1 \beta$, iPLA $A_{2}$ for iNOS, and JNK and p38 for $\left.\mathrm{COX}-2^{16,17,19}\right)$. Although $\mathrm{NF}-\kappa \mathrm{B}$ is a primary regulator of both inflammatory and type 1 IFN gene expression, a second effector pathway appears to provide the selectivity for the individual target genes. Type 1 IFN expression is associated with a regulatory role for IRF 3 and IRF7. ${ }^{13,50}$ This is in contrast to the secondary pathways described above for iNOS, COX-2, and IL-1. These findings suggest that mechanisms in addition to the classical type 1 IFN antiviral pathways may participate in the regulation of gene expression in response to virus infection. Consistent with this hypothesis, herpes simplex virus uses both dsRNA sensor-dependent (mda-5, MAVS) and dsRNA sensor-independent pathways for the regulation of antiviral gene expression. ${ }^{49}$ The dsRNA sensordependent pathways participate in the expression of type 1 IFN, whereas dsRNA sensor-independent pathways, yet to be identified, control TNF expression. ${ }^{49}$ Further, Aldridge et $\mathrm{al}^{51}$ have shown that recruitment of dendritic cells with elevated production of TNF and iNOS is associated with enhanced clearance of pathogenic strains of influenza virus.

Previous studies have shown that RIG-I and mda-5 recognize viral dsRNA produced during replication in infected cells, ${ }^{4,5}$ and that mda-5 is selective for RNA produced by Picornaviridae viruses such as EMCV. ${ }^{29} \mathrm{~A}$ major target gene of RIG-I and mda-5 activation is type 1 IFN, and consistent with these previous studies, we show that macrophages deficient in mda- 5 have attenuated IFN $\beta$ mRNA accumulation in response to EMCV infection. TLR3 is another dsRNA sensor that controls the production of type 1 IFNs. ${ }^{9,52}$ TLR3 requires multimerization and an acidic $\mathrm{pH}$ for activation. ${ }^{53}$ Labeling studies have shown that dsRNA rapidly colocalizes with TLR3 and late 
A

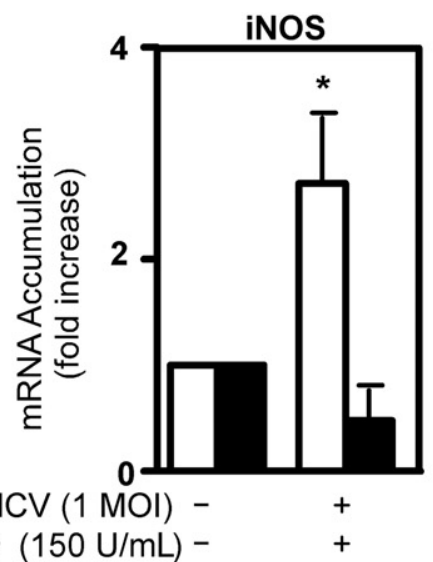

$\mathrm{B}$

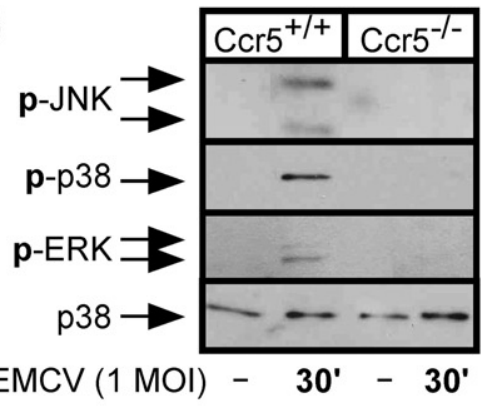

cox-2

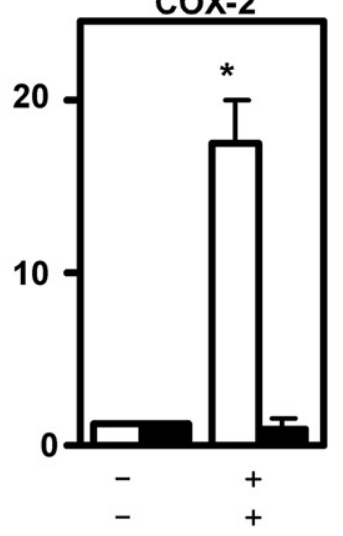

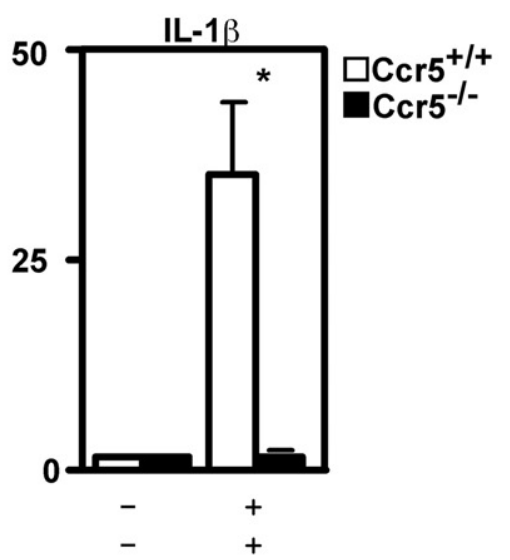

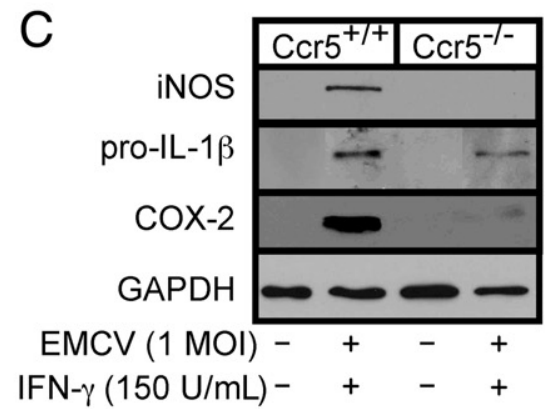

D

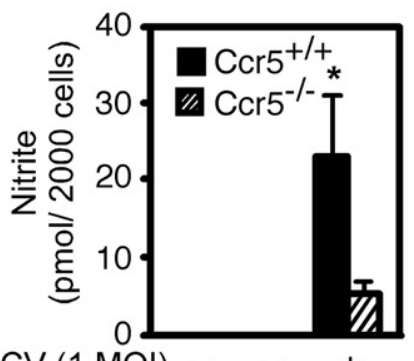

E

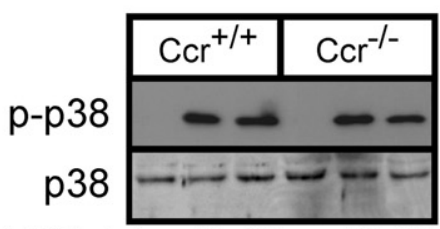

$10 \mathrm{ng} / \mathrm{mL} \operatorname{LPS}(\mathrm{min})-1530-1530$

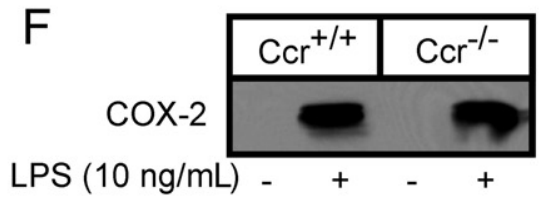

$\operatorname{EMCV}(1 \mathrm{MOI})-\quad+$

IFN- $\gamma(150 \mathrm{U} / \mathrm{mL})-++$

Figure 7. Attenuation in the activation of macrophages isolated from Ccr5-deficient macrophages in response to EMCV infection. Naive peritoneal macrophages isolated from $\mathrm{Crr}^{-/-}$and $\mathrm{Ccr}^{+/+}$mice were treated for 4 hours with or without EMCV + IFN- $\gamma$, total RNA was isolated, and iNOS, COX-2, and IL- $\beta$ mRNA accumulation was evaluated by real-time PCR analysis. mRNA accumulation was normalized to GAPDH levels (A). The stimulatory effects of EMCV ( \pm IFN- $\gamma$ ) on JNK, p38, and ERK phosphorylation [30 minutes (B)], the expression of iNOS, IL-1 $\beta$, and COX-2 [24 hours (C)], and the accumulation of nitrite [24 hours, (D)] by macrophages isolated from $\mathrm{Ccr}^{-1-}$ and $\mathrm{Ccr}^{+/+}$mice. Total p38 (B) and GAPDH (C) levels are shown as loading controls for these Western blots. LPS stimulates p38 phosphorylation (E) and COX-2 expression [24 hours, (F)] to similar levels in macrophages isolated from wild-type and Ccr5-deficient mice. Results are representative of three independent experiments $(\mathbf{B}, \mathbf{C}, \mathbf{E}$, and $\mathbf{F})$ or the average \pm SEM $(\mathbf{A}$ and $\mathbf{D})$ of three independent experiments. $\left({ }^{*} P<0.05\right.$ comparing the differences between macrophages from $\mathrm{Ccr}^{+/+}$and $\mathrm{Ccr}^{-/-}$mice).

endosomal markers as early as 30 minutes after its addition to cell cultures. ${ }^{54}$ Although these studies temporally coordinate TLR3 activation with EMCV-stimulated signaling events, the absence of TLR3 does not modify the inflammatory response of macrophages to EMCV infection for COX-2, ${ }^{19}$ iNOS, or IL-1 $\beta$ expression (this study). Overall, our findings are consistent with the many studies showing that type 1 IFN production in response to virus infection is dependent on known dsRNA sensors such as mda-5 and TLR3. 6,13,55 In addition, we also provide evidence that, much like the response of TNF production by HSV-infected macrophages, ${ }^{49}$ EMCV stimulation of inflammatory genes such as iNOS, COX-2, and IL-1 appears to occur via an alternative pathway.
Although the pathways that regulate inflammatory gene expression in response to EMCV have been characterized, the identity of the upstream receptor(s) responsible for activating these pathways has been elusive. In this study, we provide evidence that the chemokine receptor Ccr5 plays a central role in regulating this alternative pathway that controls inflammatory gene expression in response to EMCV infection. Antibody neutralization of Ccr5 attenuates the stimulatory actions of EMCV on ERK, JNK, and p38 phosphorylation, NF- $\kappa \mathrm{B}$ activation, and iNOS, COX-2, and IL- $1 \beta$ expression by mouse macrophages. Consistent with the inhibitory actions of Ccr5 antibody neutralization, the activation of MAP kinase and the induction of inflammatory gene ex- 
A

B

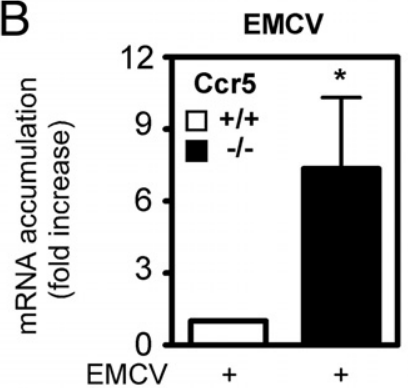

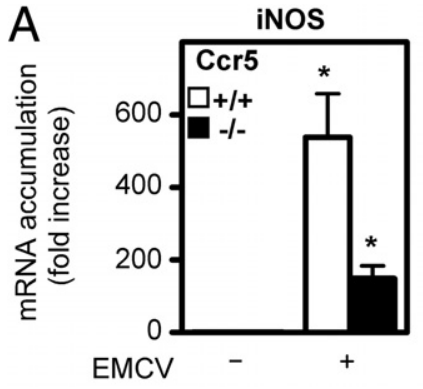

coX-2

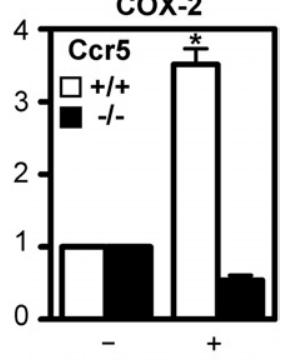

C

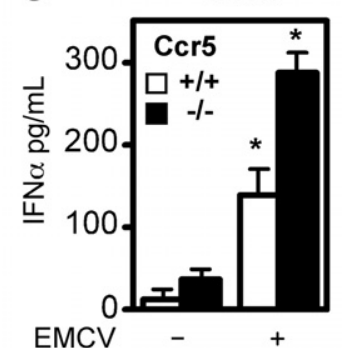

Figure 8. Inflammatory gene expression after EMCV infection is attenuated in vivo in mice lacking Ccr5. Naive macrophages were harvested from $\mathrm{CCr}^{+/+}$and $\mathrm{Ccr}^{-/-}$mice 20 hours after i.p. administration of EMCV. Total RNA was isolated, and iNOS and COX-2 mRNA accumulation, normalized to GAPDH mRNA levels, was determined by real-time PCR (A). EMCV RNA accumulates to levels sevenfold higher in macrophages isolated from Ccr5deficient mice as compared to macrophages from wild-type control mice (B), and this correlates with enhanced serum levels of IFN $\alpha$ in mice lacking Ccr5, as compared to wild-type controls (C). Serum IFN $\alpha$ levels from control and EMCV-infected animals were determined by ELISA 20 hours after infection. Results are the average \pm SEM of 6 individual mice/condition $(\mathbf{A}-\mathbf{C})$. ( ${ }^{*} P<$ 0.05 comparing the differences between macrophages from $\mathrm{Ccr}^{+/+}$and $\mathrm{Ccr}^{-1-}$ mice)

pression are attenuated in macrophages lacking Ccr5 compared to macrophages from wild-type mice. Inflammatory gene expression seems to participate in the antiviral response, because EMCV infection of Ccr5-deficient mice results in attenuation in iNOS and COX-2 expression by peritoneal macrophages, and this occurs under conditions in which there is a sevenfold increase in EMCV viral RNA accumulation compared to wild-type controls. Associated with the increase in EMCV viral RNA load is an increase in the serum accumulation of type 1 IFN in Ccr5-deficient mice compared to wild-type control mice.

A number of studies have shown that interactions of virus with a host cell surface receptors is sufficient to activate intracellular signaling cascades independent of dsRNA accumulation. As examples, replication-deficient viruses have been shown to induce cytokine production in an NF- $\kappa \mathrm{B}$-dependent manner, ${ }^{56}$ and a tegument protein of herpes simplex virus appears to participate in the regulation of TNF expression by macrophages. ${ }^{57} \mathrm{We}$ have shown that EMCV capsid protein is sufficient to activate $\mathrm{ERK}$ and the transcription factors $\mathrm{NF}-\kappa \mathrm{B}$ and CREB, and stimulates the expression of iNOS and IL-1. ${ }^{17}$ In the current study, we show that p38 and JNK are also activated by EMCV capsid protein and that this capsid protein is able to stimulate the expression of COX-2 (Figure 4). We now provide evidence that Ccr5, a surface receptor expressed on macrophages, is capable of transducing signals from EMCV capsid protein interac- tion with macrophages that are responsible for regulating inflammatory gene expression in response to EMCV infection. The identification of Ccr5 as a receptor that senses EMCV capsid protein is consistent with the ability of this receptor to recognize HIV and to interact with bacterially derived hsp 70, resulting in immune activation. ${ }^{24,27,58} \mathrm{Ccr} 5$ is a promiscuous receptor that can recognize multiple ligands, including the chemokines MIP- $1 \alpha$ and MIP- $1 \beta$, RANTES, MCP-2, HCC- 1 , and HCC-4. ${ }^{21,22}$ Although multiple chemokines are known to activate Ccr5, and EMCV is known to stimulate chemokine expression, ${ }^{59,60}$ it is unlikely that chemokines (such as RANTES) produced after EMCV infection are responsible for the activation of macrophages in a paracrine or autocrine manner. Importantly, EMCV stimulates MAP kinase activation as early as 15 minutes after infection, whereas the accumulation of RANTES mRNA is much slower, first detectable approximately 2 to 4 hours after EMCV infection (see Supplemental Figure S1 at http:// ajp.amjpathol.org). These findings temporally disassociate EMCV-induced signaling (MAP kinase and NF- $\mathrm{B}$ activation) from Ccr5 ligand mRNA accumulation.

Although Ccr5 is required for activation of proinflammatory signaling cascades, it is not required for EMCV replication in macrophages, unlike its role in HIV infection. Total PEC isolated from $\mathrm{CCr}^{-/-}$mice 20 hours after i.p. injection of EMCV showed an approximately sevenfold increase in the amount of viral mRNA, as compared to PEC isolated from wild-type mice also infected with EMCV (Figure 7B). Thus, although inflammatory gene expression is greatly reduced or absent in $\mathrm{Ccr} 5^{-1-} \mathrm{PEC}$, there is an increase in the level of virus present. These findings, which are consistent with the observation by Tyner et $\mathrm{al}^{44}$ who showed that $\mathrm{C} c r 5^{-/-}$mice have a markedly reduced clearance of Sendai virus, suggest that the absence of inflammatory gene expression in response to EMCV infection in Ccr5-deficent mice may allow for enhanced infectivity and replication of EMCV. Consistent with this hypothesis is enhanced production of type 1 IFNs in EMCV-infected Ccr5-deficient mice as compared to wild-type controls (Figure 8B). In vitro analysis of viral replication was not assessed, because isolated macrophages are a poor host for EMCV, and it has been shown that IFN production must be blocked to allow for appreciable virus replication. ${ }^{58}$

The presence of an intact type 1 IFN response in Ccr5-deficient mice, despite the absence of inflammatory gene expression (Figures 7 and 8), can be directly contrasted to the responses observed in macrophages isolated from mda-5- and TLR3-deficient mice. In both mda-5- and TLR3-deficient mice, inflammatory gene expression is still observed, whereas type 1 IFN responses are severely attenuated (Figures 1, 2, and 3). In conclusion, our results suggest that Ccr5 functions in a novel sensing pathway that results in the induction of proinflammatory gene expression that may serve to attenuate viral replication until the type 1 IFN response is initiated by the classical viral RNA sensing pathways. 


\section{Acknowledgments}

We thank Colleen Kelly Bratcher for expert technical assistance and Dr. Marco Colonna (Washington University, St. Louis, MO) for providing wild-type and mda-5-deficient macrophages. This study is dedicated to the memory of Dylan McGraw.

\section{References}

1. Jacobs BL, Langland JO: When two strands are better than one: the mediators and modulators of the cellular responses to doublestranded RNA. Virology 1996, 219:339-349

2. Gale M Jr, Katze MG: Molecular mechanisms of interferon resistance mediated by viral-directed inhibition of PKR, the interferon-induced protein kinase. Pharmacol Ther 1998, 78:29-46

3. Wu S, Kaufman RJ: A model for the double-stranded RNA (dsRNA)dependent dimerization and activation of the dsRNA-activated protein kinase PKR. J Biol Chem 1997, 272:1291-1296

4. Kang DC, Gopalkrishnan RV, Wu Q, Jankowsky E, Pyle AM, Fisher PB: mda-5: an interferon-inducible putative RNA helicase with double-stranded RNA-dependent ATPase activity and melanoma growthsuppressive properties. Proc Natl Acad Sci U S A 2002, 99:637-642

5. Yoneyama M, Kikuchi M, Natsukawa T, Shinobu N, Imaizumi T, Miyagishi M, Taira K, Akira S, Fujita T: The RNA helicase RIG-I has an essential function in double-stranded RNA-induced innate antiviral responses. Nat Immunol 2004, 5:730-737

6. Sun $Q$, Sun L, Liu HH, Chen X, Seth RB, Forman J, Chen ZJ: The specific and essential role of MAVS in antiviral innate immune responses. Immunity 2006, 24:633-642

7. Matsumoto M, Funami K, Tanabe M, Oshiumi H, Shingai M, Seto $Y$, Yamamoto A, Seya T: Subcellular localization of Toll-like receptor 3 in human dendritic cells. J Immunol 2003, 171:3154-3162[erratum appears in $\mathrm{J} \mathrm{Immunol} \mathrm{2003,} \mathrm{171:4934]}$

8. Alexopoulou L, Holt AC, Medzhitov R, Flavell RA: Recognition of double-stranded RNA and activation of NF-kappaB by Toll-like receptor 3. Nature 2001, 413:732-738

9. Stetson DB, Medzhitov R: Type I interferons in host defense. Immunity 2006, 25:373-381

10. Schulz O, Diebold SS, Chen M, Naslund TI, Nolte MA, Alexopoulou L, Azuma YT, Flavell RA, Liljestrom P, Reis e Sousa C: Toll-like receptor 3 promotes cross-priming to virus-infected cells. Nature 2005, 433 : 887-892

11. Liou HC, Baltimore D: Regulation of the NF-kappa B/rel transcription factor and I kappa B inhibitor system. Curr Opin Cell Biol 1993, 5:477-487

12. Andrejeva J, Childs KS, Young DF, Carlos TS, Stock N, Goodbourn S, Randall RE: The $V$ proteins of paramyxoviruses bind the IFN-inducible RNA helicase, mda-5, and inhibit its activation of the IFN-beta promoter. Proc Natl Acad Sci U S A 2004, 101:17264-17269

13. Onoguchi K, Yoneyama M, Fujita T: Retinoic acid-inducible gene-Ilike receptors. J Interferon Cytokine Res 2011, 31:27-31

14. Samuel CE: Innate immunity minireview series: making biochemical sense of nucleic acid sensors that trigger antiviral innate immunity. J Biol Chem 2007, 282:15313-15314

15. Steer SA, Corbett JA: The role and regulation of COX-2 during viral infection. Viral Immunol 2003, 16:447-460

16. Maggi LB Jr, Moran JM, Buller RM, Corbett JA: ERK activation is required for double-stranded $\mathrm{RNA}$ - and virus-induced interleukin-1 expression by macrophages. J Biol Chem 2003, 278:16683-16689

17. Moran JM, Buller RM, McHowat J, Turk J, Wohltmann M, Gross RW, Corbett JA: Genetic and pharmacologic evidence that calcium-independent phospholipase A2beta regulates virus-induced inducible nitric-oxide synthase expression by macrophages. J Biol Chem 2005, 280:28162-28168

18. Maggi LB Jr, Moran JM, Scarim AL, Ford DA, Yoon JW, McHowat J, Buller RM, Corbett JA: Novel role for calcium-independent phospholipase $A(2)$ in the macrophage antiviral response of inducible nitricoxide synthase expression. J Biol Chem 2002, 277:38449-38455

19. Steer SA, Moran JM, Christmann BS, Maggi LB Jr, Corbett JA: Role of MAPK in the regulation of double-stranded RNA- and encephalomyo- carditis virus-induced cyclooxygenase-2 expression by macrophages. J Immunol 2006, 177:3413-3420

20. Moran JM, Moxley MA, Buller RM, Corbett JA: Encephalomyocarditis virus induces PKR-independent mitogen-activated protein kinase activation in macrophages. J Virol 2005, 79:10226-10236

21. Lederman MM, Penn-Nicholson A, Cho M, Mosier D: Biology of CCR5 and its role in HIV infection and treatment. JAMA 2006, 296:815-826

22. Oppermann M: Chemokine receptor CCR5: insights into structure, function, and regulation. Cell Signal 2004, 16:1201-1210

23. Raport CJ, Gosling J, Schweickart VL, Gray PW, Charo IF: Molecular cloning and functional characterization of a novel human CC chemokine receptor (CCR5) for RANTES, MIP-1beta, and MIP-1alpha. J Biol Chem 1996, 271:17161-17166

24. Balter M: A second coreceptor for HIV in early stages of infection. Science 1996, 272:1740

25. Deng H, Liu R, Ellmeier W, Choe S, Unutmaz D, Burkhart M, Di Marzio P. Marmon S, Sutton RE, Hill CM, Davis CB, Peiper SC, Schall TJ, Littman DR, Landau NR: Identification of a major co-receptor for primary isolates of HIV-1. Nature 1996, 381:661-666

26. Wu L, Gerard NP, Wyatt R, Choe H, Parolin C, Ruffing N, Borsetti A, Cardoso AA, Desjardin E, Newman W, Gerard C, Sodroski J: CD4induced interaction of primary HIV-1 gp120 glycoproteins with the chemokine receptor CCR-5. Nature 1996, 384:179-183

27. Floto RA, MacAry PA, Boname JM, Mien TS, Kampmann B, Hair JR, Huey OS, Houben EN, Pieters J, Day C, Oehlmann W, Singh M, Smith KG, Lehner PJ: Dendritic cell stimulation by mycobacterial Hsp70 is mediated through CCR5. Science 2006, 314:454-458

28. Maggi LB Jr, Heitmeier MR, Scheuner D, Kaufman RJ, Buller RM, Corbett JA: Potential role of PKR in double-stranded RNA-induced macrophage activation. EMBO J 2000, 19:3630-3638

29. Gitlin L, Barchet W, Gilfillan S, Cella M, Beutler B, Flavell RA, Diamond MS, Colonna M: Essential role of mda-5 in type I IFN responses to polyriboinosinic: polyribocytidylic acid and encephalomyocarditis picornavirus. Proc Natl Acad Sci U S A 2006, 103:8459-8464

30. Beckerman KP, Rogers HW, Corbett JA, Schreiber RD, McDaniel ML, Unanue ER: Release of nitric oxide during the $T$ cell-independent pathway of macrophage activation. Its role in resistance to Listeria monocytogenes. J Immunol 1993, 150:888-895

31. Green LC, Wagner DA, Glogowski J, Skipper PL, Wishnok JS, Tannenbaum SR: Analysis of nitrate, nitrite, and [15N]nitrate in biological fluids. Anal Biochem 1982, 126:131-138

32. Bae YS, Eun HM, Yoon JW: Genomic differences between the diabetogenic and nondiabetogenic variants of encephalomyocarditis virus. Virology 1989, 170:282-287

33. Heitmeier MR, Scarim AL, Corbett JA: Interferon-gamma increases the sensitivity of islets of Langerhans for inducible nitric-oxide synthase expression induced by interleukin 1. J Biol Chem 1997, 272 : 13697-13704

34. Laemmli UK: Cleavage of structural proteins during the assembly of the head of bacteriophage T4. Nature 1970, 227:680-685

35. Pfaffl MW: A new mathematical model for relative quantification in real-time RT-PCR. Nucleic Acids Res 2001, 29:e45

36. Meylan E, Tschopp J: Toll-like receptors and RNA helicases: two parallel ways to trigger antiviral responses. Mol Cell 2006, 22:561569

37. Nathan C, Xie QW: Regulation of biosynthesis of nitric oxide. J Biol Chem 1994, 269:13725-13728

38. Heitmeier MR, Scarim AL, Corbett JA: Double-stranded RNA-induced inducible nitric-oxide synthase expression and interleukin-1 release by murine macrophages requires NF-kappaB activation. J Biol Chem 1998, 273:15301-15307

39. Iordanov MS, Wong J, Bell JC, Magun BE: Activation of NF-kappaB by double-stranded RNA (dsRNA) in the absence of protein kinase $R$ and RNase $L$ demonstrates the existence of two separate dsRNAtriggered antiviral programs. Mol Cell Biol 2001, 21:61-72

40. Smirnov YA, Rodrigues-Molto MP, Famadas MT: Protein-RNA interaction in encephalomyocarditis virus as revealed by UV light-induced covalent linkages. J Virol 1983, 45:1048-1055

41. Martin LR, Duke GM, Osorio JE, Hall DJ, Palmenberg AC: Mutational analysis of the mengovirus poly $(\mathrm{C})$ tract and surrounding heteropolymeric sequences. J Virol 1996, 70:2027-2031

42. Duque $H$, Palmenberg AC: Epitope mapping of monoclonal antibodies raised to recombinant Mengo 3D polymerase. Virus Genes 1996 , 13:159-168 
43. Alvarez S, Serramia MJ, Fresno M, Munoz-Fernandez M: Human immunodeficiency virus type 1 envelope glycoprotein 120 induces cyclooxygenase-2 expression in neuroblastoma cells through a nuclear factor-kappaB and activating protein-1 mediated mechanism. J Neurochem 2005, 94:850-861

44. Tyner JW, Uchida O, Kajiwara N, Kim EY, Patel AC, O'Sullivan MP, Walter MJ, Schwendener RA, Cook DN, Danoff TM, Holtzman MJ: CCL5-CCR5 interaction provides antiapoptotic signals for macrophage survival during viral infection. Nat Med 2005, 11:1180-1187

45. Williams BR: PKR; a sentinel kinase for cellular stress. Oncogene 1999, 18:6112-6120

46. Nishiya T, DeFranco AL: Ligand-regulated chimeric receptor approach reveals distinctive subcellular localization and signaling properties of the Toll-like receptors. J Biol Chem 2004, 279:19008-19017

47. Kawai T, Akira S: Innate immune recognition of viral infection. Nat Immunol 2006, 7:131-137

48. Kawai T, Akira S: Antiviral signaling through pattern recognition receptors. J Biochem 2007, 141:137-145

49. Melchjorsen J, Rintahaka J, Soby S, Horan KA, Poltajainen A, Ostergaard L, Paludan SR, Matikainen S: Early innate recognition of herpes simplex virus in human primary macrophages is mediated via the MDA5/MAVS-dependent and MDA5/MAVS/RNA polymerase III-independent pathways. J Virol 2010, 84:11350-11358

50. Hiscott J: Triggering the innate antiviral response through IRF-3 activation. J Biol Chem 2007, 282:15325-15329

51. Aldridge JR Jr, Moseley CE, Boltz DA, Negovetich NJ, Reynolds C, Franks J, Brown SA, Doherty PC, Webster RG, Thomas PG: TNF/ iNOS-producing dendritic cells are the necessary evil of lethal influenza virus infection. Proc Natl Acad Sci U S A 2009, 106:5306-5311
52. Stetson DB, Medzhitov R: Antiviral defense: interferons and beyond. J Exp Med 2006, 203:1837-1841[erratum appears in J Exp Med 2006, 203:2215]

53. de Bouteiller O, Merck E, Hasan UA, Hubac S, Benguigui B, Trinchieri G, Bates EE, Caux C: Recognition of double-stranded RNA by human toll-like receptor 3 and downstream receptor signaling requires multimerization and an acidic pH. J Biol Chem 2005, 280:38133-38145

54. Johnsen IB, Nguyen TT, Ringdal M, Tryggestad AM, Bakke O, Lien E, Espevik T, Anthonsen MW: Toll-like receptor 3 associates with c-Src tyrosine kinase on endosomes to initiate antiviral signaling. EMBO J 2006, 25:3335-3346

55. Onomoto K, Onoguchi K, Takahasi K, Fujita T: Type I interferon production induced by RIG-I-like receptors. J Interferon Cytokine Res 2010, 30:875-881

56. Hiscott J, Nguyen TL, Arguello M, Nakhaei P, Paz S: Manipulation of the nuclear factor-kappaB pathway and the innate immune response by viruses. Oncogene 2006, 25:6844-6867

57. Paludan SR, Mogensen SC: Virus-cell interactions regulating induction of tumor necrosis factor alpha production in macrophages infected with herpes simplex virus. J Virol 2001, 75:10170-10178

58. Tsan MF, Smith K, Gao B: Assessing the quality of human research protection programs: the experience at the Department of Veterans Affairs. IRB 2010, 32:16-19

59. Tsuji K, Yamamoto S, Ou W, Nishi N, Kobayashi I, Zaitsu M, Muro E, Sadakane $Y$, Ichimaru T, Hamasaki Y: dsRNA enhances eotaxin-3 production through interleukin-4 receptor upregulation in airway epithelial cells. Eur Respir J 2005, 26:795-803

60. Abrahams VM, Visintin I, Aldo PB, Guller S, Romero R, Mor G: A role for TLRs in the regulation of immune cell migration by first trimester trophoblast cells. J Immunol 2005, 175:8096-8104 